Atmos. Chem. Phys., 13, 10143-10157, 2013

www.atmos-chem-phys.net/13/10143/2013/

doi:10.5194/acp-13-10143-2013

(c) Author(s) 2013. CC Attribution 3.0 License.

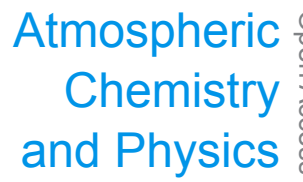

(c) (1)

\title{
Cloud-resolving simulations of mercury scavenging and deposition in thunderstorms
}

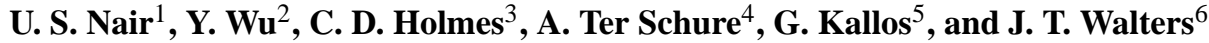 \\ ${ }^{1}$ Department of Atmospheric Science, University of Alabama in Huntsville, Huntsville, Alabama, USA \\ ${ }^{2}$ Earth System Science Center, University of Alabama in Huntsville, Huntsville, Alabama, USA \\ ${ }^{3}$ Department of Earth System Science, University of California, Irvine, California, USA \\ ${ }^{4}$ Electric Power Research Institute, Palo Alto, California, USA \\ ${ }^{5}$ School of Physics, University of Athens, Athens, Greece \\ ${ }^{6}$ Southen Company Services, Birmingham, Alabama, USA
}

Correspondence to: Y. Wu (wuy@nsstc.uah.edu)

Received: 26 November 2012 - Published in Atmos. Chem. Phys. Discuss.: 8 February 2013

Revised: 16 August 2013 - Accepted: 24 August 2013 - Published: 15 October 2013

\begin{abstract}
This study examines dynamical and microphysical features of convective clouds that affect mercury $(\mathrm{Hg})$ wet scavenging and concentrations in rainfall. Using idealized numerical model simulations in the Regional Atmospheric Modeling System (RAMS), we diagnose vertical transport and scavenging of soluble $\mathrm{Hg}$ species - gaseous oxidized mercury (GOM) and particle-bound mercury ( $\mathrm{HgP})$, collectively $\mathrm{Hg}(\mathrm{II})$ - in thunderstorms under typical environmental conditions found in the Northeast and Southeast United States (US). Mercury scavenging efficiencies from various initial altitudes are diagnosed for a case study of a typical strong convective storm in the Southeast US. Assuming that soluble mercury concentrations are initially vertically uniform, the model results suggest that $60 \%$ of mercury deposited to the surface in rainwater originates from above the boundary layer $(>2 \mathrm{~km}$ ). The free troposphere could supply a larger fraction of mercury wet deposition if GOM and $\mathrm{HgP}$ concentrations increase with altitude. We use radiosonde observations in the Northeast and Southeast to characterize three important environmental characteristics that influence thunderstorm morphology: convective available potential energy (CAPE), vertical shear $(0-6 \mathrm{~km})$ of horizontal wind (SHEAR) and precipitable water (PW). The Southeast US generally has lower SHEAR and higher CAPE and PW. We then use RAMS to test how PW and SHEAR impact mercury scavenging and deposition, while keeping the initial $\mathrm{Hg}$ (II) concentrations fixed in all experiments. We found that the mercury concentration in rainfall is sensitive to SHEAR
\end{abstract}

with the nature of sensitivity differing depending upon the PW. Since CAPE and PW cannot be perturbed independently, we test their combined influence using an ensemble of thunderstorm simulations initialized with environmental conditions for the Northeast and Southeast US. These simulations, which begin with identical $\mathrm{Hg}$ (II) concentrations, predict higher mercury concentrations in rainfall from thunderstorms forming in the environmental conditions over the Southeast US compared to the Northeast US. A final simulation of a stratiform rain event produces lower mercury concentrations than in thunderstorms forming in environments typical of the Southeast US. The stratiform cloud scavenges mercury from the lowest $\sim 4 \mathrm{~km}$ of the atmosphere, while thunderstorms scavenge up to $\sim 10 \mathrm{~km}$.

\section{Introduction}

Lakes, rivers and coastal waters throughout the United States contain mercury at levels that harm wildlife and people who consume fish from these waters (Liu et al., 2008; KarounaRenier et al., 2008; EPA, 2011). Monitoring has established that atmospheric transport and deposition is a major source of mercury to many of these watersheds (Lindberg et al., 2007; Northeast Regional Mercury Total Maximum Daily Load, 2007). In the Eastern United States, wet deposition is largest over the Gulf Coast region (Fig. 1), particularly during the summer months, coinciding with the 


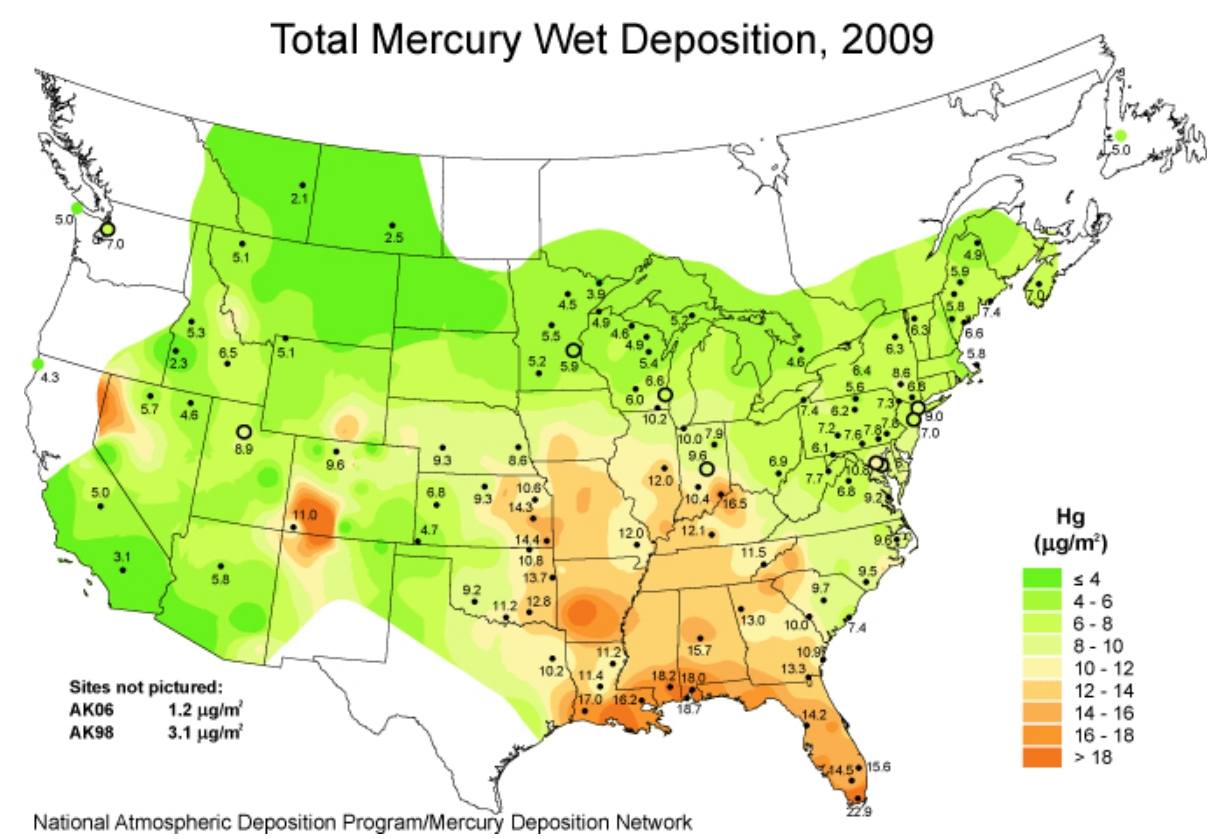

Fig. 1. Total mercury wet deposition for the year 2009. Note the regional maximum along the Gulf Coast. This is a consistent feature that is also present during other years (from National Atmospheric Deposition Program/Mercury Deposition Network, 2010).

peak of convective storm activity. Indeed, rainwater samples from thunderstorms contain higher mercury concentrations than rain from non-convective or weakly convective storms (Holmes et al., 2010b; Holmes, 2013). Unlike other watersoluble anthropogenic pollutants, including sulfate and nitrate, the region of high mercury wet deposition does not overlap the peak emission region, which is much farther north (EPA, 2013).

The causes of enhanced mercury concentrations in Southeast US thunderstorm rain remain unclear. The enhancement might be due to the large volumes of boundary layer air that are sucked into the convective updraft, where scavenging can occur (Dvonch et al., 1998, 2005; White et al., 2009). Alternatively, deep convective thunderstorms may scavenge from a high-altitude reservoir of soluble mercury that is inaccessible to weak or non-convective storms (Guentzel et al., 2001; Selin and Jacob, 2008; Landing et al., 2010). Soluble mercury species $(\mathrm{Hg}(\mathrm{II}))$ consist of gaseous oxidized mercury $(\mathrm{GOM})$ and particle-bound mercury $(\mathrm{HgP})$, both of which can be scavenged by cloud water and precipitation. These species are emitted directly from coal-fired power plants and some other industrial sources and can also be produced by oxidation of elemental mercury $(\operatorname{Hg}(0))$, the dominant form of atmospheric mercury. The Eastern US has a large number of surface-based mercury emissions sources, whereas aircraft have documented an increase of oxidized mercury concentration with altitude (Sillman et al., 2007; Talbot et al., 2008; Slemr et al., 2009; Lyman and Jaffe, 2012). Both factors may plausibly influence mercury concentrations in thunderstorm rainfall. The interplay and importance of these factors, how- ever, depends on the dynamics of thunderstorms and the meteorological environment. Some regional and global models predict enhanced wet deposition in the Southeast US, but generally underestimate its observed magnitude and perform more poorly in this region than other parts of the US, perhaps because they rely on subgrid parameterizations for rain and convection (Bullock et al., 2009; Selin and Jacob, 2008; Zhang et al., 2012).

Past observational and cloud-resolving model studies of other trace gases and aerosols have found that their transport and scavenging during convection depends strongly on their solubility. Highly soluble gases, like $\mathrm{HNO}_{3}$ and GOM, are efficiently scavenged into cloud droplets and rain (Mari et al., 2000; Barth et al., 2001; Yin et al., 2001), while lowsolubility gases, such as $\mathrm{CO}$ and $\mathrm{O}_{3}$, can be transported from the boundary layer to the upper troposphere in convective updrafts (Dickerson et al., 1987; Cotton et al., 1995; Halland et al., 2009). In the frozen upper portions of deep convective clouds, the scavenging and removal of soluble gas also depends on whether dissolved gas stays in solution when liquid drops freeze onto hail or graupel, as $\mathrm{HNO}_{3}$ does (Barth et al., 2001, 2007; Yin et al., 2001). GOM observations in high-altitude clouds are not available, but surface observations of GOM during riming and snowfall conditions suggest that dissolved GOM is also retained during freezing, but not scavenged from gas by ice (Douglas et al., 2008; Johnson et al., 2008; Sigler et al., 2009). Particle-bound mercury is found on polluted urban, sulfate and sea salt aerosols (Murphy et al., 2006; Feddersen et al., 2012) and thus behaves similarly to other hydrophilic aerosols inside clouds. These 
hydrophilic aerosols partition into cloud water via nucleation or impaction scavenging and are thus scavenged with similarly high efficiency to $\mathrm{HNO}_{3}$ (Murakami et al., 1983; Jensen and Charlson, 1984; Gillani et al., 1995). Washout by rain and snow below clouds further enhances wet deposition of both soluble gases and aerosols (Levine and Schwartz, 1982; Feng et al., 2007, 2009). Prior studies also show the viability of utilizing cloud-resolving models in understanding processes related to removal and transport of trace species by convective storms (Barth et al., 2007; Halland et al., 2009).

Regional differences in wet scavenging efficiency, which might affect mercury deposition patterns, have not been systematically examined, but cloud dynamics literature provides some insights. Environmental characteristics, such as atmospheric instability, impact the mixing of air from surroundings into convective clouds (Cohen et al., 2000) and thunderstorms forming in moist marine environments better scavenge soluble trace gases from the atmosphere compared to those that form in a continental setting due to their slower updrafts and efficient conversion of cloud water to rain (Yin et al., 2001). In addition, Cotton et al. (1995) found that cloud venting, or transport of boundary layer air by storms to upper levels, varies substantially as a function of storm type (Cotton et al., 1995), with ordinary thunderstorms being less efficient compared to mesoscale convective systems, excluding mesoscale convective complexes.

This study uses cloud-resolving simulations of convective and non-convective rainstorms to examine mercury transport within clouds, including its scavenging by precipitation and deposition to the ground. Despite the similar solubility and microphysical interactions with convective clouds described above, oxidized mercury and $\mathrm{HNO}_{3}$ exhibit important environmental differences that justify our specific focus on mercury: mercury emissions and wet deposition are not collocated, unlike nitrogen and sulfur; and oxidized mercury concentrations are commonly higher in the upper troposphere than in the boundary layer, unlike most other pollutants. Simulations here identify scavenging pathways and test how ambient atmospheric conditions affect scavenging, based on the well-known ways that these properties affect thunderstorm dynamics, morphology and microphysics (e.g., Cotton et al., 1995). Through analysis of radiosonde data, we identify atmospheric conditions - specifically, convective available potential energy, shear and precipitable water - that differ between the Northeast and Southeast United States. With simulations of thunderstorms occurring under each of these regions, and assuming the same initial distribution of GOM and $\mathrm{HgP}$, we show that meteorological controls on cloud dynamics and microphysics is a factor that need to be considered in explaining the regional enhancement of mercury deposition in the Southeast.

\section{Methods}

\subsection{Meteorological data}

Three important factors that potentially modulate mercury wet deposition in thunderstorms are the nature of the updraft, vertical variation of horizontal wind in the environment and hydrometeor mixing ratio within clouds. A substantial amount of the air within thunderstorms originates from within the PBL (Dickerson et al., 1987; Cotton et al., 1995). Thus the mass flux and the incorporation of PBL air into the thunderstorm are influenced by the updraft vertical velocity. Small-scale turbulent and larger-scale cloud entrainment (Fig. 2) also incorporates free tropospheric air into thunderstorms (Knupp and Cotton, 1985). Further, there are two forms of small-scale turbulent entrainment: lateral and cloud top entrainment. Of these, cloud top entrainment is more effective and is driven by fluid shear instabilities that engulf environmental air along the cloud edge caused by horizontal variations in updraft strength. Subsequent evaporation of cloud droplets within engulfed air leads to downdrafts that penetrate and mix environmental air over depths of 1-2 km (Knupp and Cotton, 1985). Larger-scale systematic lateral entrainment, under conditions without environmental shear, occurs due to increasing vertical velocity with height and associated lateral flow driven by mass continuity requirements. In sheared environments, high pressure perturbation on the upshear side of thunderstorms diverts the environmental flow and causes a relatively unmixed cloud region. However, an associated low pressure perturbation feature on the down shear side causes flow reversal and wake entrainment, mixing environmental air into thunderstorms. Unlike turbulent entrainment, wake entrainment is organized at cloud scale. In addition, the magnitude of pressure perturbations that drive wake entrainment flow is proportional to vertical shear of horizontal wind and also the gradient of vertical velocity. Knupp and Cotton (1995) note that the relative strengths of the turbulent scale and large-scale entrainment are potentially modulated by environmental characteristics, with large-scale entrainment becoming more dominant as storm vigor increases. Numerical modeling studies of Cohen (2000) do indeed show such modulation of cloud entrainment processes, with stronger updrafts in unstable environments being better able to entrain undisturbed environmental air compared to weak updrafts in a more stable environment.

In the context of the physical process settings discussed above, the experimental design utilized in this study focuses on thunderstorm morphology and evolution based on a parameter space defined by three variables, namely convective available potential energy (referred from hereon as CAPE), vertical shear (vertical component of gradient) of horizontal wind (referred from hereon as SHEAR) and precipitable water (referred from hereon as PW). Note that CAPE is the potential energy that is available to a parcel ascending from the level of free convection to the equilibrium level. CAPE 


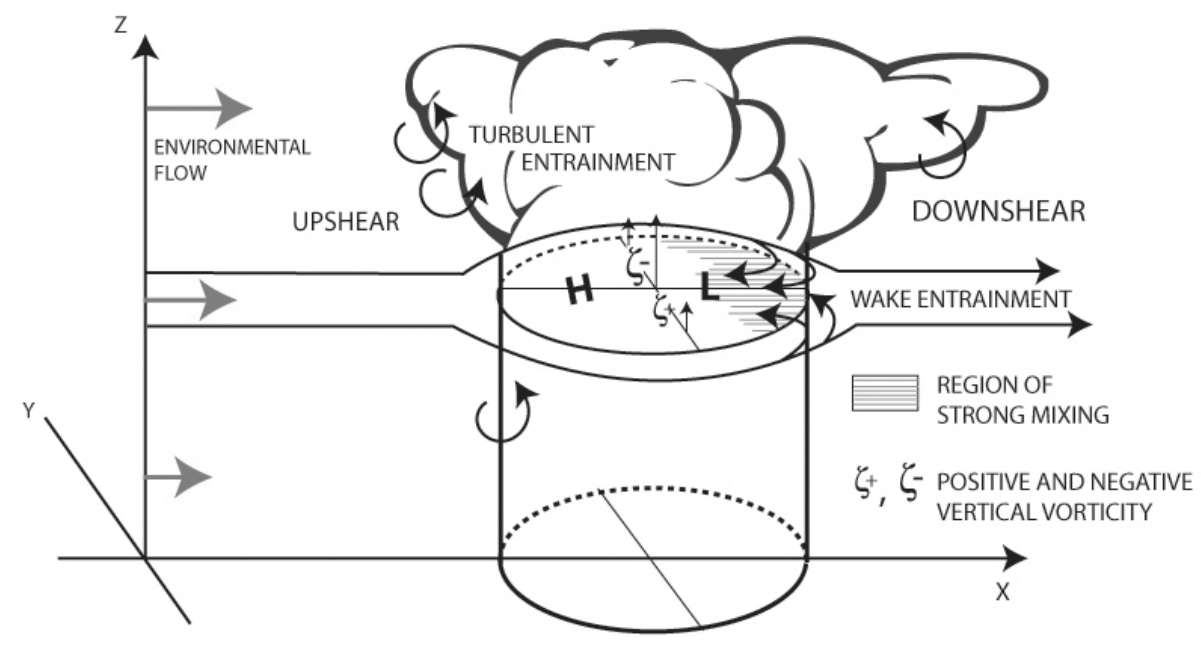

Fig. 2. Schematic of entrainment processes in convective clouds (Adapted from Knupp and Cotton, 1985). Turbulent eddies along the lateral and top boundaries of the cloud entrain environmental air into the cloud. Convective cloud acts as a flow obstruction and leads to positive $(H)$ and negative pressure perturbation $(L)$ on the upshear and downshear side. Flow patterns associated with clockwise $\left(\zeta^{+}\right)$and counter clockwise $\left(\zeta^{-}\right)$rotating vortex couplets that from the southern and northern flanks of the updraft (vertically pointing arrows within the cloud) also reinforce the wake entrainment.

Table 1. The name and discrete value ranges of CAPE, SHEAR and PW considered in this study.

\begin{tabular}{lcccccccccc}
\hline Variable & \multicolumn{3}{c}{ CAPE $\left(\mathrm{J} \mathrm{kg}^{-1}\right)$} & & \multicolumn{3}{c}{ SHEAR $\left(\mathrm{m} \mathrm{s}^{-1}\right)$} & \multicolumn{3}{c}{ PW (mm) } \\
\hline Category name & $\mathrm{c} 1000$ & $\mathrm{C} 1500$ & $\mathrm{c} 2000$ & $\mathrm{c} 2500$ & $\mathrm{~s} 5$ & $\mathrm{~s} 10$ & $\mathrm{~s} 15$ & $\mathrm{p} 40$ & $\mathrm{p} 50$ & $\mathrm{p} 60$ \\
Mean value & 1000 & 1500 & 2000 & 2500 & 5 & 10 & 15 & 40 & 50 & 60 \\
Range & \pm 100 & \pm 100 & \pm 100 & \pm 100 & \pm 2 & \pm 2 & \pm 2 & \pm 2 & \pm 2 & \pm 2 \\
\hline
\end{tabular}

is indicative of the atmospheric instability and value ranges of less than $1000 \mathrm{~J} \mathrm{~kg}^{-1}, 1000-2500 \mathrm{~J} \mathrm{~kg}^{-1}$ and greater than $2500 \mathrm{~J} \mathrm{~kg}^{-1}$ are considered weakly unstable, moderately unstable and largely unstable, respectively. CAPE is also indicative of the maximum updraft speed since it is the amount of energy available for conversion to kinetic energy. As discussed previously, higher SHEAR leads to better organized flows, especially those related to larger-scale entrainment. PW is the total amount of water vapor available within an atmospheric column and is expressed as the height (usually in $\mathrm{mm}$ ) of the column of liquid water obtained from condensing all the water vapor within an atmospheric column of cross section $1 \mathrm{~m}^{2}$. PW impacts the amount of condensate present within the updraft and thus the vertical velocity. The three parameter space used in this study is a subset of higher dimensional parameter spaces utilized by prior numerical modeling studies of thunderstorm morphology and evolution (Cohen, 2000; McCaul Jr. and Weissman, 2001; McCaul Jr. et al., 2005; Cohen and McCaul Jr., 2006; Kirkpatrick et al., 2007; Kirkpatrick et al., 2011). Note that these studies do show that CAPE, SHEAR and PW modulate cloud mass flux, cloud entrainment and hydrometeor mass distribution in thunderstorms and all of these processes are important to wet deposition removal of atmospheric mercury.
The three-parameter space utilized in this study is defined by discrete ranges of CAPE, SHEAR and PW (Table 1). The ranges represent different possible combinations of these parameters. Occurrences of these parameter combinations are determined by analyzing radiosonde observations from five Northeast sites $\left(\sim 40^{\circ} \mathrm{N}\right)$ and three Southeast sites $\left(\sim 30^{\circ} \mathrm{N}\right)$ for the summer months 2001-2011 (Fig. 3) using the methodology of Nair et al. (2002).

\subsection{Model description}

The Regional Atmospheric Modeling System (RAMS) is a non-hydrostatic finite difference numerical model used to simulate atmospheric phenomena ranging from cloud scale to mesoscale (Cotton et al., 2003). In this study, the RAMS version 6.0 is configured to simulate individual thunderstorms, their internal convective motions and resultant precipitation. Similar to McCaul Jr. et al. (2005), we use an idealized experimental design to highlight the role of environmental conditions on storm morphology and mercury. The horizontal domain consists of flat terrain extending $120 \mathrm{~km} \times 120 \mathrm{~km}$ with a spacing of $500 \mathrm{~m}$ in each dimension. The vertical resolution is $20 \mathrm{~m}$ near the ground, increasing to $1000 \mathrm{~m}$ at high altitudes, up to model top at $23.5 \mathrm{~km}$. Cyclic lateral boundary conditions are used. 


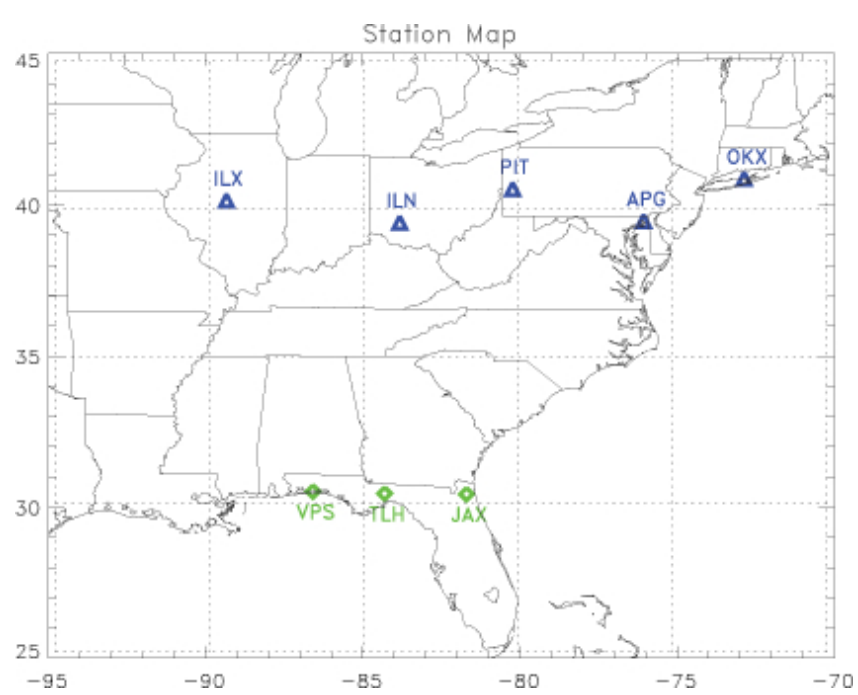

Fig. 3. Launch sites for the radiosondes used in the present study. Blue triangles denote the northern stations located at around $40^{\circ} \mathrm{N}$, green diamonds denote the southern stations near $30^{\circ} \mathrm{N}$.

Two soluble mercury species, GOM and $\mathrm{HgP}$, are included in the simulations here. These species are transported by bulk air motions and within precipitation. Exchange of GOM and $\mathrm{HgP}$ between air, cloud water and precipitation follow a scheme for nitric acid and inert aerosols (Seinfeld and Pandis, 2006) as implemented in RAMS by Voudouri and Kallos (2007). Within clouds, GOM concentrations in cloud water are in Henry's law equilibrium with the interstitial air, while $\mathrm{HgP}$ is assumed to reside entirely in the condensed water or ice. The dissolved fractions of GOM and $\mathrm{HgP}$ are then transported downward by hydrometeors at the same rate that precipitation forms. Below clouds, GOM is scavenged by rain following the Levine and Schwartz (1982) mechanism for nitric acid (see also Eq. 20.25 of Seinfeld and Pandis, 2006). Falling rain and ice scavenge $\mathrm{HgP}$ with collision efficiencies calculated for monodisperse aerosols with diameter $300 \mathrm{~nm}$ (see Eq. 20.53 of Seinfeld and Pandis, 2006). Both GOM and $\mathrm{HgP}$ are released back to the air if hydrometeors evaporate before reaching the ground. Ice is assumed not to scavenge GOM (Sigler et al., 2009; Amos et al., 2012), so no GOM is scavenged below $-39^{\circ} \mathrm{C}$. This wet deposition scheme has been evaluated against observations from the Mercury Deposition Network (MDN) in the Eastern United States. During periods when RAMS accurately simulates precipitation amounts, the model reproduces about half of the observed variability in mercury deposition, similar to the CMAQ-Hg model (Voudouri et al., 2007).

The model is initialized with horizontally uniform vertical profiles of wind and thermodynamic variables. A warm air bubble is inserted at the surface to trigger convection and its subsequent evolution is simulated for $2 \mathrm{~h}$. Over these short timescales, atmospheric radiative transfer and landatmosphere interactions have little effect on storm develop-

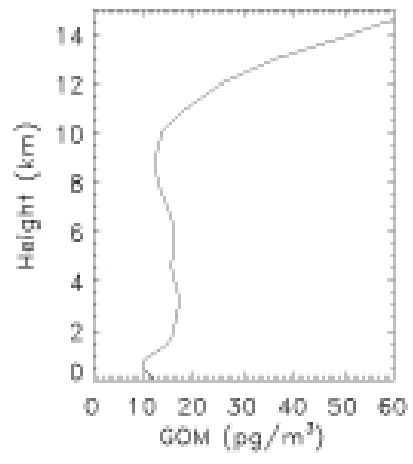

Fig. 4. Initial GOM profile for the southern sites derived from GEOS-Chem simulations. The profiles for $\mathrm{HgP}$ is same as the GOM profile.

ment and are neglected here. Chemical oxidation and reduction are also neglected because reactions in both gas and aqueous phases have time scales much longer than the duration of our simulations (Lin and Pehkonen, 1999; Subir et al., 2011). We use a detailed cloud microphysical parameterization, with prognostic equations for mixing ratios of cloud water, rain, pristine ice, snow, aggregate, graupel and hail hydrometeors (Walko et al., 1995; Myers et al., 1997).

\subsection{Initial vertical $\mathrm{Hg}$ profiles}

Initial conditions for GOM and $\mathrm{HgP}$ (Fig. 4) are for summer conditions over the Southeast US, as simulated by GEOSChem global Hg model (Holmes et al., 2010a) since vertically resolved observations of $\mathrm{GOM}$ and $\mathrm{HgP}$ are rare. The global model includes oxidation of $\mathrm{Hg}(0)$ by bromine and Coburn et al. (2011) have recently observed $\mathrm{BrO}$ in the marine boundary layer and free troposphere near our study area. The initial conditions include surface concentrations of GOM around $10 \mathrm{pg} \mathrm{m}^{-3}$, which is similar to suburban and rural observations in the Southeast US (Edgerton et al., 2006; Valente et al., 2007). The GEOS-Chem model also reproduces observed vertical gradients of $\mathrm{Hg}(0)$, including in the lower stratosphere at mid-latitudes (Holmes et al., 2010a). Simulated GOM and $\mathrm{HgP}$ concentrations near the tropopause are smaller than reported by Lyman and Jaffe (2012) $\left(120 \mathrm{pg} \mathrm{m}^{-3}\right.$ vs. $500 \mathrm{pg} \mathrm{m}^{-3}$ for total oxidized $\mathrm{Hg}$ at $15 \mathrm{~km}$ ) but show a similarly sharply increasing vertical gradient in the lower stratosphere. At higher altitudes, Lyman and Jaffe (2012) suggest that there is little $\mathrm{Hg}$ of any kind above $17 \mathrm{~km}$, due to aerosol scavenging and gravitational sedimentation. These aerosol processes are not included in the GEOS-Chem model, but the results of this work are not sensitive to this assumption because, as shown below, there is little wet scavenging from these stratospheric altitudes. In the present study, equal amounts of GOM and $\mathrm{HgP}$ are assumed for simplicity so that all differences in scavenging and deposition of these species are due to interactions with 
hydrometeors. Select simulations using uniform GOM and $\mathrm{HgP}$ initial conditions are described further below.

\subsection{Numerical modeling experiments}

Three types of experiments are conducted: (1) diagnosis of how a typical thunderstorm transports mercury vertically through advection and precipitation, including surface deposition; (2) simulations of thunderstorms that form and evolve in environments with differing combinations of CAPE, SHEAR and PW and associated sensitivity experiments to isolate the effect of SHEAR and; (3) simulation of a stratiform rainfall event to compare the efficacy of removal of mercury between deep convective and stratiform systems. The first experimental case study traces the fate of mercury, including wet deposition, during a strong thunderstorm that occurs under conditions in the Southeast US (with CAPE $=2500 \mathrm{~J} \mathrm{~kg}^{-1}$, SHEAR $=10 \mathrm{~m} \mathrm{~s}^{-1}$, and $\mathrm{PW}=60 \mathrm{~mm}$ ). Six simulations are run with uniform initial concentrations of $30 \mathrm{pg} \mathrm{m}^{-3}$ for GOM and $\mathrm{HgP}$ throughout the following altitude ranges: the entire depth of the model atmosphere (STD); planetary boundary layer (0-2 km, PBL); lower free troposphere $(2-5 \mathrm{~km}$, LFT); upper free troposphere (5-10 km, UFT); and tropopause-lower stratosphere (10-16 km, TLS). Initial GOM and $\mathrm{HgP}$ concentrations are zero elsewhere. After passage of the thunderstorm, we diagnose the final altitude distribution and deposition of mercury in each simulation.

The second type of experiments conducted examines the atmospheric removal of mercury by convective storms simulated for multiple combinations of CAPE, SHEAR and PW within the defined parameter space (Tables 1,3). Realistic initial GOM and $\mathrm{HgP}$ vertical profiles are used (Fig. 4), as described above. These simulations are conducted starting from initial meteorological conditions specified using radiosonde observations from both the Southeast and Northeast sites (Fig. 3). The following naming convention is used to identify the different simulations: $\mathrm{c} X \mathrm{~s} Y \mathrm{p} Z$ _SID, where $X, Y$ and $Z$ are the values of CAPE, SHEAR and PW, respectively, associated with the radiosonde observation used in the experiment and SID indicates the geographical location. The variable SID can be " $n$ " or " $s$ " indicating Northeast or Southeast sites. A numerical model simulation, initialized using radiosonde observations from a Southeast site and with a $1000 \mathrm{~J} \mathrm{~kg}^{-1}$ CAPE, $15 \mathrm{~m} \mathrm{~s}^{-1}$ shear and $50 \mathrm{~mm}$ PW will be referred to as c1000s15p50_s. A similar simulation, except initialized using a profile from a Northeast radiosonde site will be referred to as c1000s15p50_n. Radiosonde observations over both Northeast and Southeast are both utilized in order to account for variability related to environmental parameters in addition to CAPE, SHEAR and PW.

In the second set of experiments, for a given CAPE, response of mercury wet deposition to systematic variations in PW and SHEAR will be examined (Fig. 5). For example two simulations where CAPE and PW are held constant
Table 2. Average and standard deviation of CAPE, SHEAR, and PW over the Eastern United States during 2001-2011. See Fig. 2 for radiosonde sites used in the analysis.

\begin{tabular}{cccc}
\hline $\begin{array}{c}\text { Location } \\
\text { (profiles) }\end{array}$ & $\begin{array}{c}\text { CAPE } \\
\left(\mathrm{J} \mathrm{kg}^{-1}\right)\end{array}$ & $\begin{array}{c}\text { SHEAR } \\
\left(\mathrm{m} \mathrm{s}^{-1}\right)\end{array}$ & $\begin{array}{c}\text { PW } \\
(\mathrm{mm})\end{array}$ \\
\hline South $(n=4631)$ & $1324.0 \pm 896.5$ & $6.1 \pm 3.6$ & $46.8 \pm 9.2$ \\
North $(n=3770)$ & $813.9 \pm 1046.7$ & $13.6 \pm 5.3$ & $37.4 \pm 8.6$ \\
\hline
\end{tabular}

but SHEAR varies will be compared (e.g., c2500s10p50_s versus c2500s5p50). An implicit assumption in such comparisons is that the majority of the variability is due to the parameter that is altered between the experiments. However, in practice it is difficult to get two atmospheric profiles that have two parameters exactly the same. Another possibility is to artificially modify the atmospheric profile to modify just one characteristic. Since CAPE and PW are interconnected variables it is difficult to change $\mathrm{PW}$ without altering CAPE. However, for a given combination of CAPE and PW, differing SHEAR profiles may be imposed by scaling the wind profile. Such shear sensitivity experiments will be conducted by imposing a uniform scaling factor of 0.5 to the wind profile throughout the depth of the atmosphere. The sensitivity simulation will be denoted by adding a prefix of _0.5SHEAR to the name of the experiment for which the wind profile is modified by a uniform scale factor. The validity of the assumption implicit in the comparisons of the second set of experiments will be tested utilizing the SHEAR sensitivity experiments.

The third type of experiments simulates a stratiform precipitation event, to compare the efficacy of mercury removal by stratiform versus convective cloud systems. It is difficult to initiate a stratiform event in an idealized experimental framework used for simulating convective events. For the stratiform simulation, RAMS was initialized using the spatially heterogeneous North American Model (NAM) atmospheric analysis and incorporating realistic atmospheric forcing. A nested grid structure was employed in these experiments to establish an inner domain similar to that used in the idealized simulations for convective events. The RAMS is integrated until a stratiform cloud deck is established and maintained for a time period of two hours, consistent with the life time of the convective events considered in this study.

\section{Results}

\subsection{Frequency of occurrence of radiosonde observations as a function of parameter space}

Analysis of radiosonde observations found that, compared to the Northeast sites, the mean CAPE and PW is $62 \%$ and $25 \%$ higher, and SHEAR is $125 \%$ smaller at the Southeast sites (Table 2). Cumulative frequency distributions of CAPE 

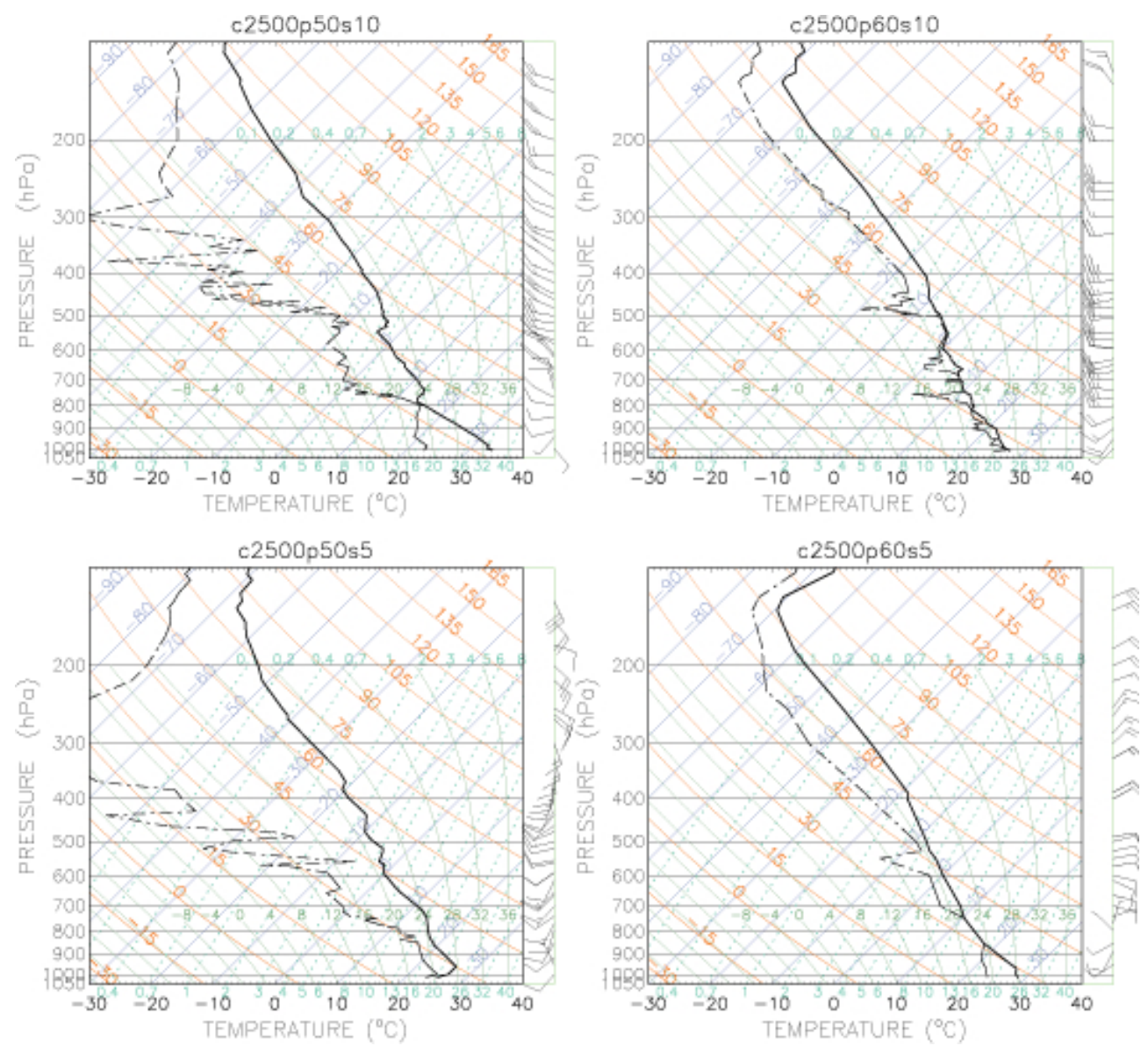

Fig. 5. Thermodynamic and wind profiles used to initialize numerical model simulations experiments c2500p50s10, c2500p60s10, c2500p50s5 and c2500p60s5 are shown in top left, top right, bottom left and bottom right panels respectively.

Table 3. Co-occurrence of specific value ranges of CAPE (c1000, c1500, c2000 and c2500), SHEAR (s5 and s10) and PW (p40 and p50) at the southern and northern sites for summer months of 20002011. The counts of the co-occurrence for the southern sites are given after the CAPE case names and followed by that of the northern sites given in the parenthesis. The co-occurrences for a specific SHEAR and PW category are listed below all the CAPE cases in the category.

\begin{tabular}{rrr}
\hline & $\mathrm{p} 50$ & $\mathrm{p} 60$ \\
\hline s5 & $\mathbf{c 1 0 0 0}-73(2)$ & $\mathbf{c 1 0 0 0}-11(0)$ \\
& $\mathbf{c 1 5 0 0}-36(0)$ & $\mathbf{c 1 5 0 0}-21(1)$ \\
$\mathbf{c 2 0 0 0}-36(0)$ & $\mathbf{c 2 0 0 0}-9(0)$ \\
$\mathbf{c 2 5 0 0}-\frac{13(0)}{158(2)}$ & $\mathbf{c 2 5 0 0 -} \frac{14(0)}{55(1)}$ \\
\hline \multirow{2}{*}{$\mathbf{s 1 0}$} & $\mathbf{c 1 0 0 0}-29(12)$ & $\mathbf{c 1 0 0 0}-4(2)$ \\
& $\mathbf{c 1 5 0 0}-19(4)$ & $\mathbf{c 1 5 0 0}-6(0)$ \\
& $\mathbf{c 2 0 0 0}-20(2)$ & $\mathbf{c 2 0 0 0}-3(0)$ \\
& $\mathbf{c 2 5 0 0}-9(3)$ & $\mathbf{c 2 5 0 0}-4(1)$ \\
& $77 \overline{(21)}$ & $17(3)$ \\
\hline
\end{tabular}

(Fig. 6a) for soundings with low to high instability, show that the atmosphere of the Southeast is climatologically more unstable than the Northeast, with $\sim 65 \%$ of the soundings having CAPE of $\leq 2000 \mathrm{~J} \mathrm{~kg}^{-1}$ at the Northeast sites versus only $\sim 19 \%$ at the Southeast sites. The highest number of soundings at the Southeast sites falls within the CAPE range $2000-2500 \mathrm{~J} \mathrm{~kg}^{-1}$ followed by $2500-3000 \mathrm{~J} \mathrm{~kg}^{-1}$ range. At the Northeast sites, $92 \%$ and $20 \%$ of the radiosonde observations have PW values $\leq 50 \mathrm{~mm}$ and SHEAR $\leq 8 \mathrm{~m} \mathrm{~s}^{-1}$, respectively (Fig. 6b, c), compared to $\sim 61 \%$ at $69 \%$ the Southeast sites (Fig. 6b). The contrast between the sites becomes even more evident when co-occurrences of specific ranges of CAPE, PW and SHEAR are considered (Tables 2, 3). For example, for moderate PW $(50 \mathrm{~mm})$ and all values of CAPE, Southeast sites are most likely to have low SHEAR (s5), while Northeast sites are likely to have higher SHEAR (s10) (Table 3). Of the categories examined here, only the combination of highest SHEAR $\left(15 \mathrm{~m} \mathrm{~s}^{-1}\right)$ and lowest PW $(40 \mathrm{~mm})$ occur more frequently in the Northeast than in the Southeast.

Numerical modeling experiments discussed in the following sections will consider thunderstorm development for 

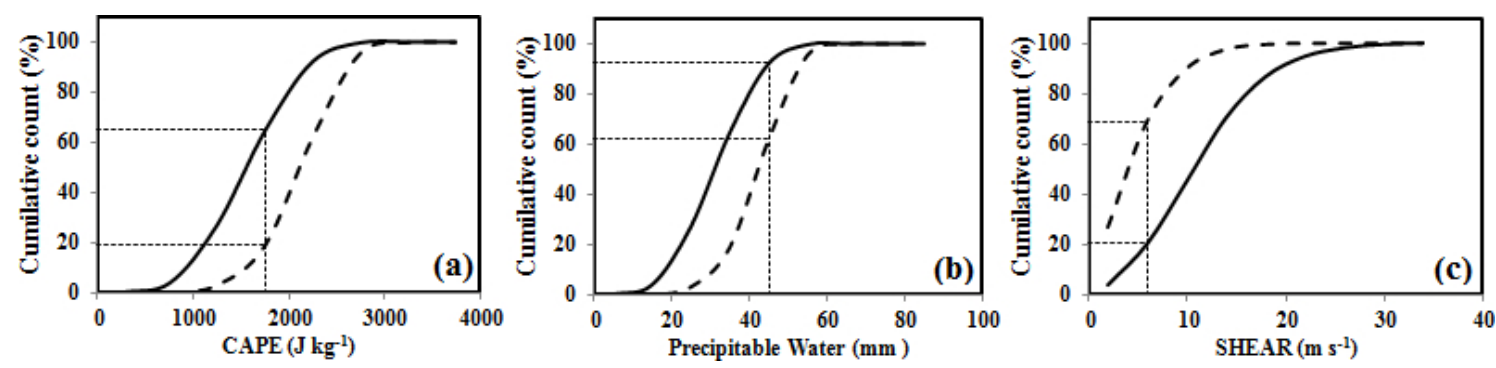

Fig. 6. Cumulative frequency distribution of (a) CAPE; (b) PW and; (c) SHEAR for the time period 2000-2011. The thick solid line is for the northern sites and the thick dashed line is for the southern sites.

Table 4. Fraction of mercury mass (\%) transported from an initial altitude to a final altitude by the passage of a thunderstorm. Transport

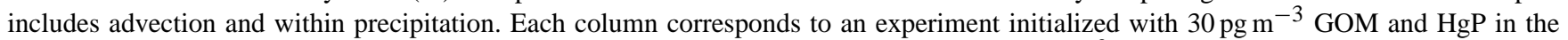
specified initial altitude range and zero elsewhere. The STD experiment has uniform $30 \mathrm{pg} \mathrm{m}^{-3}$ initial mixing ratios through the entire column. The total mass of mercury in each experiment is $71.3 \mathrm{ng} \mathrm{m}^{-2}$ (PBL), $98.8 \mathrm{ng} \mathrm{m}^{-2}$ (LFT), $148 \mathrm{ng} \mathrm{m}^{-2}$ (UFT), $191 \mathrm{ng} \mathrm{m}^{-2}$ (TLS), $180.9 \mathrm{ng} \mathrm{m}^{-2}$ (MST), and $690 \mathrm{ng} \mathrm{m}^{-2}$ (STD).

\begin{tabular}{lrrrrrr}
\hline & \multicolumn{5}{c}{ Initial altitude } \\
\cline { 2 - 7 } Final altitude & $\begin{array}{r}\text { PBL } \\
(0-2 \mathrm{~km})\end{array}$ & $\begin{array}{r}\text { LFT } \\
(2-5 \mathrm{~km})\end{array}$ & $\begin{array}{r}\text { UFT } \\
(5-10 \mathrm{~km})\end{array}$ & $\begin{array}{r}\text { TLS } \\
(10-16 \mathrm{~km})\end{array}$ & $\begin{array}{r}\text { MST } \\
(16-23 \mathrm{~km})\end{array}$ & $\begin{array}{r}\text { STD } \\
(0-23 \mathrm{~km})\end{array}$ \\
\hline $16-23 \mathrm{~km}$ & 0.0 & 0.0 & 0.0 & 5.7 & 96.2 & 26.9 \\
$10-16 \mathrm{~km}$ & 0.0 & 0.0 & 1.5 & 88.4 & 3.1 & 25.3 \\
$5-10 \mathrm{~km}$ & 0.0 & 0.7 & 83.4 & 2.6 & 0.0 & 18.7 \\
$2-5 \mathrm{~km}$ & 1.3 & 62.8 & 3.3 & 0.3 & 0.0 & 10.1 \\
$0-2 \mathrm{~km}$ & 47.2 & 2.2 & 0.3 & 0.0 & 0.0 & 5.3 \\
Surface deposition and & 51.5 & 34.4 & 11.5 & 3.0 & 0.7 & 13.7 \\
$\left(\right.$ deposited mass, pg m $\left.^{-3}\right)$ & $(36.7)$ & $(33.6)$ & $(17.0)$ & $(5.6)$ & $(1.3)$ & $(94.7)$ \\
\hline
\end{tabular}

environments with CAPE of $\sim 2500 \mathrm{~J} \mathrm{~kg}^{-1}$ (highly unstable conditions) which occur frequently over the Southeast (Fig. 6a). Since the unstable conditions also frequently cooccur with smaller values of $\operatorname{SHEAR}\left(5 \mathrm{~m} \mathrm{~s}^{-1}\right)$ over the Southeast sites (Table 3, Fig. 6), numerical modeling experiments are utilized to contrast how mercury concentrations in thunderstorm rainfall is altered in a higher shear environment more prevalent over the Northeast.

\subsection{Diagnosis of mercury wet deposition in thunderstorms}

We next develop a physical understanding of how thunderstorms transport mercury through a case study of a single storm containing GOM and $\mathrm{HgP}$ starting at various altitudes. The c2500s10p60 initial conditions produce a vigorous storm and relatively high wet removal and deposition of atmospheric mercury. This experiment shows that the surface wet deposition is most sensitive to GOM and $\mathrm{HgP}$ in the boundary layer (Table 4). Approximately $50 \%$ of mercury mass initially in the PBL is removed through wet deposition. The fraction of mercury deposited to the surface declines with altitude, being $34 \%$ for the lower free troposphere, $11.5 \%$ for the upper tropospheric region and $3.5 \%$ for the tropopause region and above. In the STD simulation with uniform vertical distribution of GOM and $\mathrm{HgP}, \sim 60 \%$ of the mercury deposited at the surface originates from above $2 \mathrm{~km}$, with lower free troposphere layer, upper free troposphere and tropopause-lower stratosphere layers contributing $35 \%, 18 \%$ and $6 \%$, respectively. In reality, the contribution from the free troposphere under these conditions would likely be larger since GOM and $\mathrm{HgP}$ mixing ratios increase with altitude (Fig. 4; Lyman and Jaffe, 2012).

Profiles of the domain-averaged perturbation of GOM (Fig. 7a), at the end of the sensitivity experiments LFT and UFT, show an increase in GOM in the boundary layer, caused by both evaporation of precipitation reaching this layer and air mass advection (Fig. 7a). However, in the STD simulation, the gain in GOM in the boundary layer is negated by the higher magnitude of loss of GOM from within the layer. Thus, the profile of mean GOM perturbation in the STD experiment is dominated by scavenging except in the region immediately above the PBL (Fig. 7a). In the TLS, UFT and LFT experiments, some $\mathrm{HgP}$ is transported downwards (Fig. 7b), but in the STD simulation, $\mathrm{HgP}$ removal dominates at all altitudes.

Note that the largest GOM changes in the STD simulation occur at the highest altitudes (Fig. 7a), where little GOM is removed to the surface. This indicates that thunderstorms 

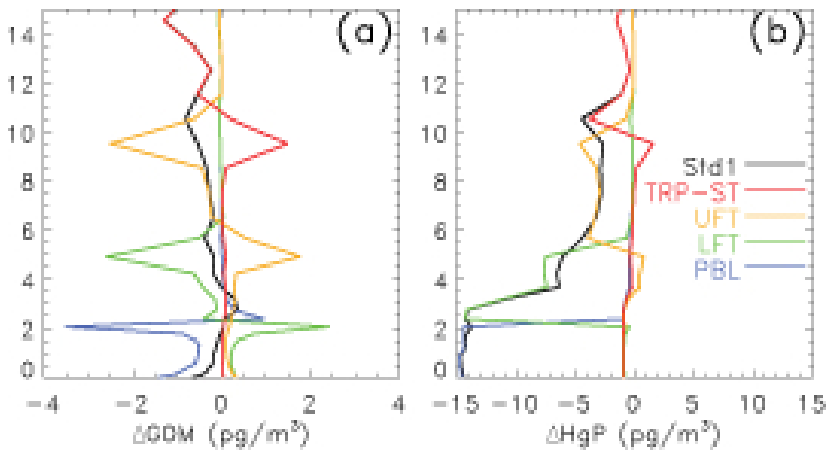

Fig. 7. Domain averaged perturbation of GOM (panel a) and $\mathrm{HgP}$ (panel b) at the end of the following simulations: PBL (blue), LFP (green), UFT (orange), TLS (red) and STD (black) sensitivity experiments.

are mixing the high altitude reservoir of oxidized mercury downwards and making it more susceptible to scavenging by subsequent storms. In areas where thunderstorms occur frequently, this could be a potential pathway for enhanced mercury wet deposition.

\subsection{Impact of convective storm morphology on mercury wet deposition and concentration in precipitation}

When comparing mercury concentrations in precipitation between different events, confounding effects of differences in amount of precipitation needs to be taken into account. Mercury concentrations in rainfall decrease approximately exponentially with rainfall amount (Holmes et al., 2010b) due to the washout effect, which is also observed for other soluble trace gases and aerosols. Numerical model simulations for parameter combinations c2500s5p50_s, c2500s10p50_s, c2500s5p60_s and c2500s10p60_s (Fig. 5) also show nearly exponential decrease of mercury in rainfall (Fig. 8a, b), similar to observations.

For a given CAPE $\left(2500 \mathrm{~J} \mathrm{~kg}^{-1}\right)$, the concentration of mercury in rainfall is sensitive to SHEAR, but the nature of the sensitivity depends upon PW. For lower PW conditions $(50 \mathrm{~mm})$, an increase in SHEAR (5 to $10 \mathrm{~m} \mathrm{~s}^{-1}$ ), leads to an increase in mercury concentrations (Fig. 8a) for lower precipitation amounts $(<13 \mathrm{~mm})$, but a reduction at higher precipitation amounts ( $>13 \mathrm{~mm})$. At higher PW conditions $(60 \mathrm{~mm}$ ) increase in SHEAR (Fig. 8b) leads to decrease in mercury concentrations for all the precipitation amounts. Nevertheless, the total mercury deposition integrated over all precipitating areas decreases with increasing SHEAR. To demonstrate that the effect is primarily due to shear, we isolate SHEAR in sensitivity experiments c2500s10p50_s_0.5SHEAR and c2500s10p60_0.5SHEAR, where the shear profiles are uniformly scaled to half the value (Fig. 8c, d). Differences in mercury concentration in rainfall between c2500s10p50_s and c2500s10p50_s_0.5SHEAR experiments (Fig. 8c) are similar to differences between ex- periments c2500s5p50_s and c2500s10p50_s experiments. Thus, the differences in mercury concentration between c2500s5p50_s and c2500s10p50_s experiments are caused primarily due to variation in SHEAR. Similarly, differences in mercury concentration between c2500s5p60_s and c2500s10p60_s cases are also explained by the variation of SHEAR (Fig. 8d).

\subsection{Vertical distribution of mercury wet deposition removal and mass flux in thunderstorms}

Spatial (domain) and temporal averages (for the time period of the simulation) of vertical profiles of hydrometeor mixing ratio (both ice and water phase), wet deposition removal of GOM and $\mathrm{HgP}$ were computed for the c2500s5p50_s, c2500s10p50_s, c2500s5p60_s and c2500s10p60_s experiments. Note that the spatial average considers only atmospheric columns where hydrometeors are present. For all the cases considered, GOM and $\mathrm{HgP}$ scavenging occurs over a deep layer of the atmosphere, extending from the surface to $\sim 10 \mathrm{~km}$ (Fig. 9). Note that the hail and graupel hydrometeors, which are classified as ice in the figure, carry some liquid water, as well as ice, and thus scavenge GOM at high altitudes where there is no rain. The scavenging of both GOM and $\mathrm{HgP}$ in the upper regions of the boundary layer and the lower tropospheric layer increases with PW.

There are substantial differences in mass flux of hydrometeors (transport of mass of hydrometeor per unit area per unit time) and mercury (GOM used as an example) between c2500s5p50_s, c2500s10p50_s, c2500s5p60_s and c2500s10p60_s experiments (Fig. 10). Both hydrometeor and GOM mass flux increases with PW (Fig. 10a, b). Scavenging of mercury (Fig. 9) and concentrations in rainfall (Fig. 8a, b) are both sensitive to hydrometeor and GOM mass flux in the $0-4 \mathrm{~km}$ layer. Note that GOM mass flux in downdrafts have magnitudes similar to those in updrafts, but the cloud mass flux associated with the downdrafts are substantially less (Fig. 9). This is indicative of transport in clear air regions or along the lateral boundary region of the thunderstorm. In all the experiments, there is enhanced GOM flux near the tropopause, despite the small cloud mass flux, because the high concentration gradients are largest at these altitudes (Fig. 4). While such sharp gradients of oxidized mercury have been observed around the tropopause (Lyman and Jaffe, 2012), the large fluxes simulated at these high altitudes have high uncertainty because of the sparse constraints on the gradient in the initial conditions. Above the tropopause, vertical $\mathrm{Hg}$ fluxes diminish quickly because the strong stratospheric temperature inversion suppresses cloud vertical motions. This also explains the negligible impact of stratospheric GOM on deposition, seen in the MST simulation above (Sect. 3.2). 

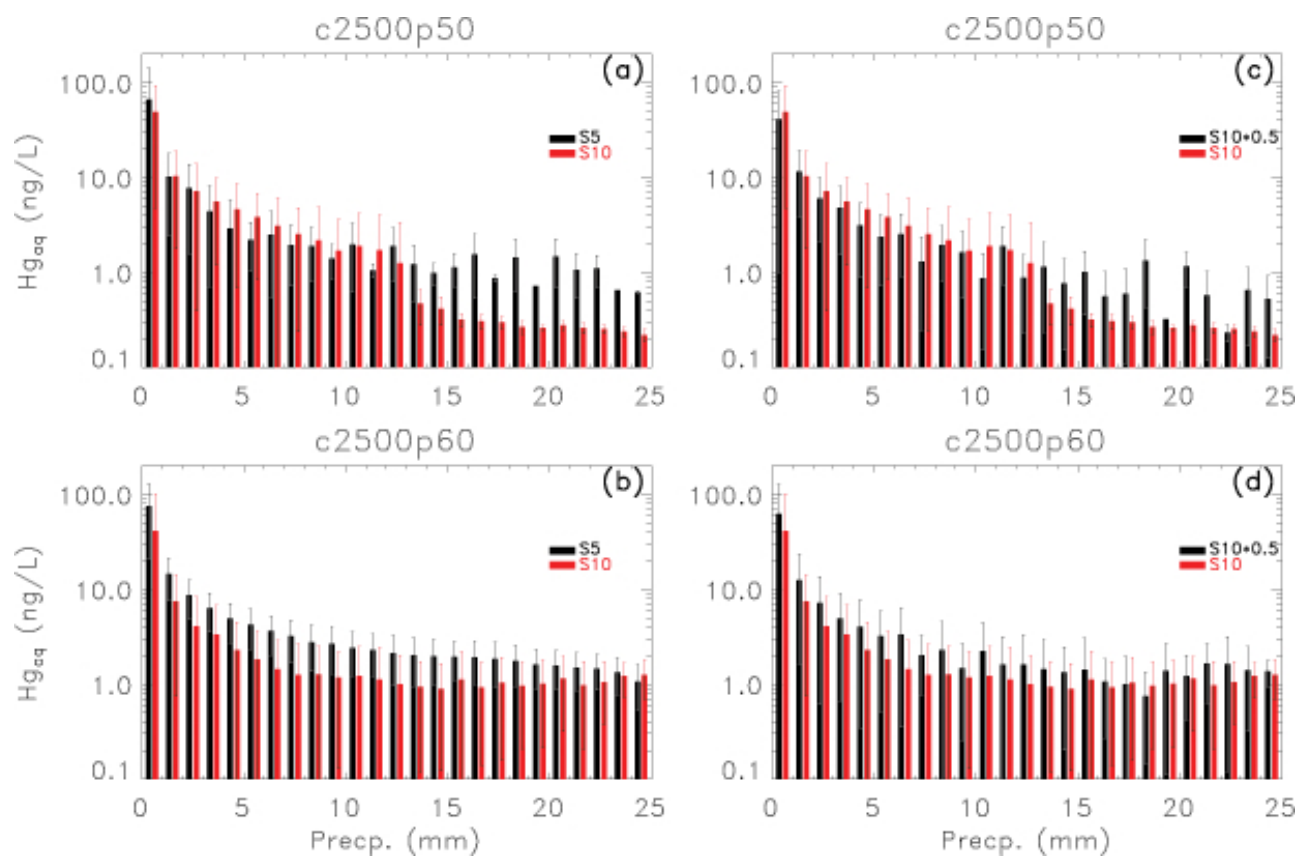

Fig. 8. Mercury concentration as a function of accumulated rainfall for (a) and (c), CAPE in c2500 and PW in p50; (b) and (d), CAPE in c2500 and PW in p60. For (a) and (b) SHEAR categories s5 (black) and s10 (red). For (c) and (d) SHEAR categories s10 (red) and divided by 2 (black).

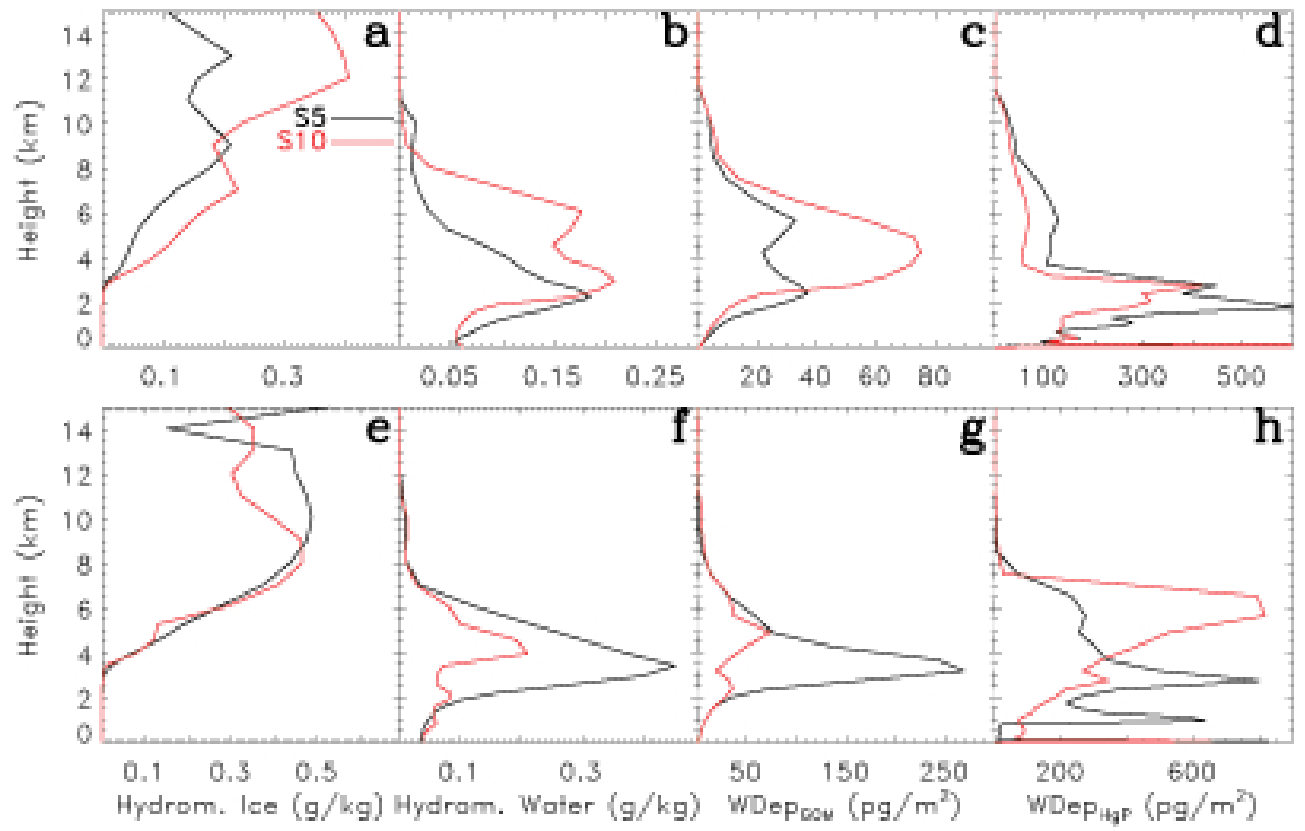

Fig. 9. Vertical average profiles of hydrometeors and scavenging in thunderstorms. (a) frozen hydrometeors; (b) rain (liquid hydrometeors); (c) net scavenging of GOM; (d) net scavenging of HgP. Category s5 is in black and s10 in red. CAPE is in c2500 for all simulations. Panels (a)-(d) are PW category p50. Panels (e)-(h) are PW category p60. Note the change of scale between the top and bottom rows. 

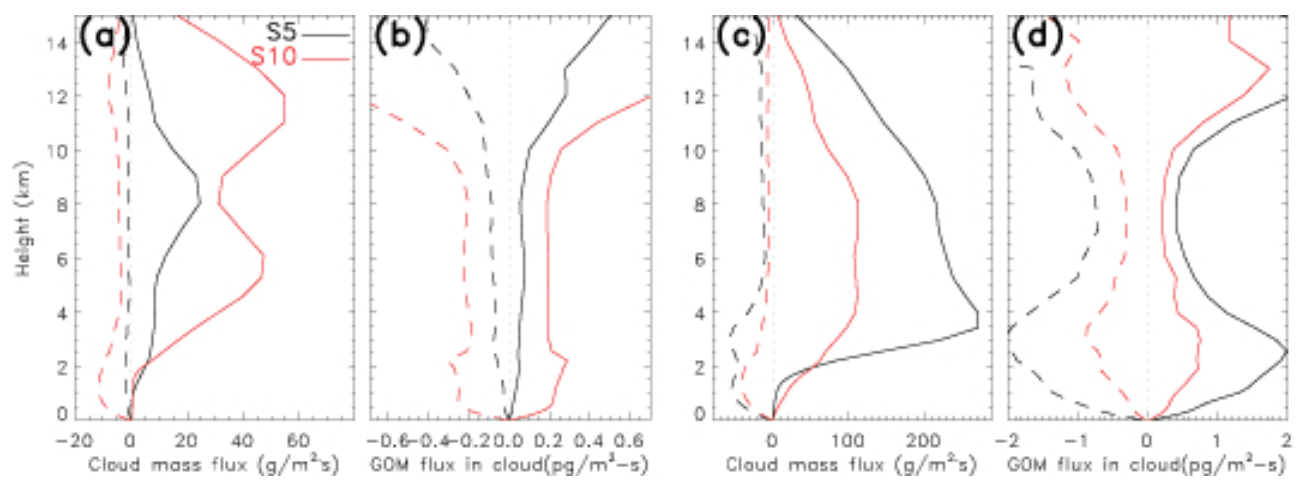

Fig. 10. Cloud mass flux and GOM flux in clouds for SHEAR categories $5 \mathrm{~m} \mathrm{~s}^{-1}$ (black) and $10 \mathrm{~m} \mathrm{~s}^{-1}$ (red). Panel (a) is average could mass flux and panel (b) is GOM mass flux in cloud for CAPE category c2500 and PW in p50. Panels (c) and (d) are the same as panels (a) and (b), except for CAPE in c2500 and PW in p60. Solid lines show updrafts while downdrafts are shown with dashed lines.
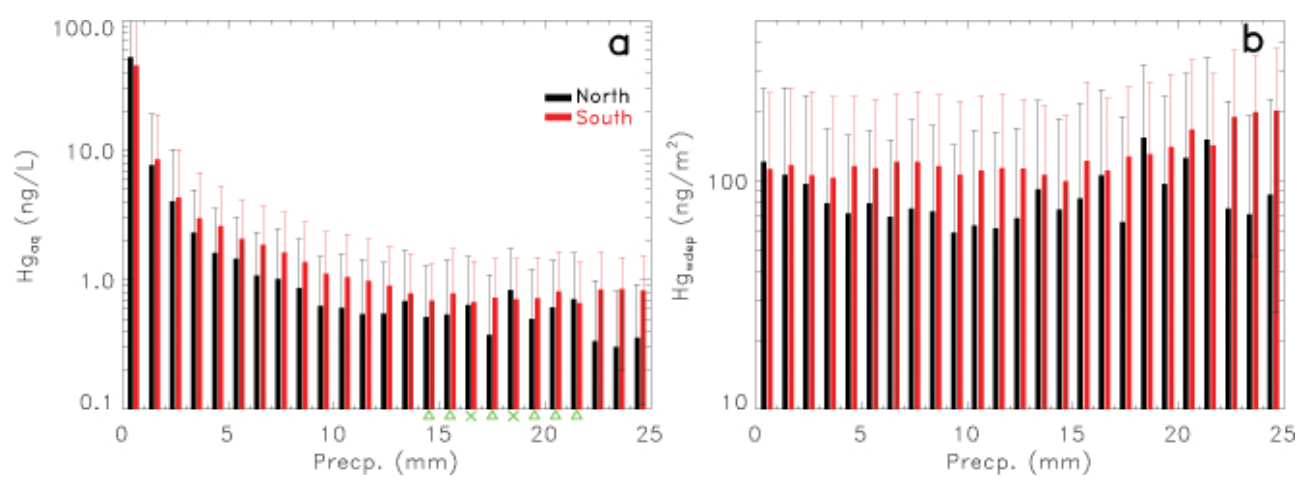

Fig. 11. Mercury concentration (a) and wet deposition (b) as a function of accumulated rainfall. The red and black bars show simulations initialized with radiosonde profiles from southern sites and northern sites, respectively.

\subsection{Comparison of mercury concentrations in rainfall in the Northeast and Southeast}

Analysis of radiosonde observations (Sect. 3.1) show that combinations of CAPE, SHEAR and PW are different over Southeast sites compared to Northeast sites (Table 6). Numerical modeling experiments also show that mercury concentration is higher for SHEAR and PW combinations that are more common in the Southeast (Sect. 3.3). However, there are other degrees of freedom that need to be considered which could mask or modulate the effects of variability of CAPE, SHEAR and PW. Therefore, an ensemble of simulations, involving thunderstorms simulated for parameter combinations that occur frequently over the Northeast and Southeast sites are compared (Fig. 11). The mercury concentration and surface wet deposition for these two different groupings are then plotted as a function of accumulated rainfall (Fig. 11). For a majority of the bins, the mean difference is statistically significant at $95 \%$ confidence level. The mean ratio of concentrations between the southern and northern sites for all the rainfall bins in Fig. 11 is $\sim 1.53$. This analysis shows that meteorological controls on storm morphology can have a large influence on mercury concentrations in rainfall and wet deposition.

\subsection{Mercury concentration in rain: comparison between stratiform and convective events}

Uptake of mercury over a deeper layer of the atmosphere is potentially one of the factors that contribute to enhanced mercury wet deposition in thunderstorms in comparison to other types of precipitation systems. Comparison between the stratiform and thunderstorm simulations c2500s5p50_s, c2500s10p50_s, c2500s5p60_s and c2500s10p60_s show higher mercury concentration in the latter, even after accounting for the dilution effect (Fig. 12). In the stratiform experiment, GOM and $\mathrm{HgP}$ scavenging only occurs below $\sim 4.5 \mathrm{~km}$ altitude (Fig. 13), whereas in thunderstorms substantial removal occurs up to $10 \mathrm{~km}$ (Fig. 9).

\section{Discussion}

This study shows that thunderstorms can remove more mercury from the atmosphere than stratiform precipitation systems. Meteorological conditions in the Southeast can favor 


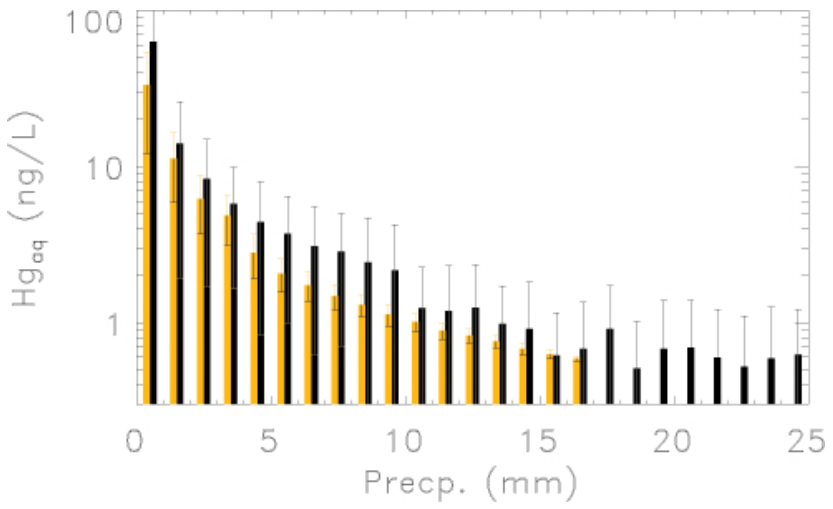

Fig. 12. Mercury concentration in rainfall from a stratiform event (yellow) and thunderstorms simulations c2500s5p50_s, c2500s10p50_s, c2500s5p60_s and c2500s10p60_s (black). All simulations are initialized with identical GOM and $\mathrm{HgP}$ conditions.

the formation of thunderstorms with microphysical and dynamic structures that enhance wet deposition removal of GOM and HgP. Sensitivity studies further show that thunderstorms can scavenge GOM and $\mathrm{HgP}$ from both the FT and PBL. If $\mathrm{Hg}$ (II) concentrations increase with altitude as suggested by aircraft observations (Sillman et al., 2007; Lyman and Jaffe, 2012), then our calculated scavenging efficiencies imply that the FT supplies the majority of mercury in wet deposition from thunderstorms, as has been hypothesized by earlier investigators (Guentzel et al., 2001; Selin and Jacob, 2008; Shanley et al., 2011). These modeling results also support the observational finding of Holmes et al. (2010b) that part of the Southeast US wet deposition enhancement could be explained by the frequency of thunderstorms and their greater scavenging. Better constraints on mercury wet scavenging processes could be provided by airborne mercury measurements in convective cloud inflow and outflow, together with modeling of specific convective events, as has been done for nitric acid (e.g., Barth et al., 2007), however these mercury data do not currently exist. The upcoming Nitrogen, Oxidants, Mercury and Aerosol Distributions, Sources and Sinks (NOMADSS) field aircraft experiment should partially fill this gap, as it is designed to evaluate mercury wet deposition, among other goals, through extensive vertical profiles and horizontal surveys of $\mathrm{Hg}$ (II) and associated trace gases over the East and Southeast US.

It is also important to consider the limitations of the modeling approach in this work. Experiments here are designed to eliminate complicating effects from large-scale dynamical forcing and chemical transformation. Thus this study does not include organized, larger-scale convective systems such as mesoscale convective systems that are initiated by dynamical forcing that is substantially different from the warm bubble initiation that are idealized counterparts of disorganized convection. The timescales and circulation patterns associated with such systems are considerably different and their

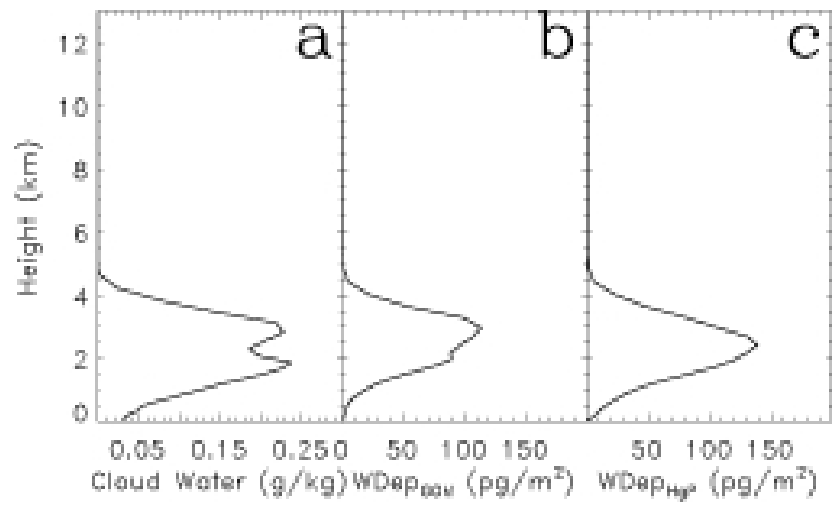

Fig. 13. Domain averaged vertical distribution of (a) hydrometeor in water phase; (b) GOM wet deposition; (c) $\mathrm{HgP}$ wet deposition for the stratiform event.

response to changes in environmental conditions, such as $\mathrm{PW}$, could therefore be substantially different, and the approach taken in this study has to be extended to actual events. Second, in numerical simulations the rainfall mercury concentration can be determined at all grid points within the domain. Observations of wet deposition are often taken at few discrete locations and a large sample size would be required to capture the spatial variability indicated by numerical simulations (Figs. 8 and 11). Oxidation of $\mathrm{Hg}(0)$ though photochemistry and aqueous phase reactions are not considered in this study and will be evaluated in future investigations. The cyclic lateral boundary condition assumed in this study is another limitation since it can reintroduce material removed though the outflow to the inflow. However, the simulations considered in this study are for short timescales, such effects are expected to be minimal.

\section{Conclusions}

Past studies suggested that tall convective thunderstorms may be responsible for the enhanced mercury deposition in the Southeast and our modeling work explores the dynamical and scavenging mechanisms at work in thunderstorms. We use simulations in the RAMS cloud-resolving model to examine the wet scavenging efficiency of mercury at various altitudes (PBL vs. FT) and to test how mercury wet deposition responds to several environmental properties that affect thunderstorm morphology (CAPE, PW and SHEAR). Simulations here include two soluble mercury species: GOM and $\mathrm{HgP}$. Their interactions with cloud water and ice are simulated based on their similarities to nitric acid and hydrophilic aerosols and also informed by surface observations of GOM and $\mathrm{HgP}$ during rain, snow and riming conditions. Observations of GOM and $\mathrm{HgP}$ in convective cloud inflow and outflow and model comparison to specific rain events could further constrain mercury wet scavenging processes, but are beyond the scope of this work. 
Using idealized simulations with uniform initial concentrations of GOM and $\mathrm{HgP}$ in several altitude ranges, we find that a typical, strong convective storm forming in environmental conditions that are common over the Southeast US can scavenge about $50 \%$ of mercury in the boundary layer $(0-2 \mathrm{~km})$ and deposit it to the surface in rainfall. Removal efficiencies are $35 \%$ or less in the free troposphere and decline with altitude. Nevertheless, if we assume that $\mathrm{Hg}$ (II) species are initially uniformly mixed vertically, then $60 \%$ of mercury deposited by the thunderstorm originates in the free troposphere, with a small contribution from the lower stratosphere. Airborne observations suggest that $\mathrm{Hg}$ (II) often increases with altitude, so the free troposphere may supply a larger fraction of mercury wet deposition in thunderstorms.

Convective storms in the Southeast US tend to form under meteorological conditions with lower SHEAR and higher CAPE and PW. In an ensemble of thunderstorm simulations initialized with meteorological conditions that occur frequently over the Northeast and Southeast US and identical initial $\mathrm{Hg}(\mathrm{II})$, mercury concentrations and deposition are higher for thunderstorm that form under environmental conditions characteristic of the Southeast. We use model sensitivity tests to evaluate the influence of SHEAR and PW on mercury scavenging, but CAPE is coupled to PW and cannot be perturbed independently in the model. When PW is high, increasing SHEAR reduces mercury concentrations for all rainfall amounts. At lower values of PW, however, increasing SHEAR decreases the mercury concentration in areas with high accumulated precipitation and increases the concentration in areas with little accumulated precipitation. Despite these complexities, higher SHEAR decreases total simulated scavenging and wet deposition of both GOM and $\mathrm{HgP}$.

In a simulation of stratiform rain, mercury concentrations in rainfall are lower than thunderstorms from the Southeast US. Substantial mercury wet scavenging occurs up to altitudes of $10 \mathrm{~km}$ in thunderstorms, whereas the stratiform system considered scavenges only over the lowest $4 \mathrm{~km}$. Overall, cloud-resolving simulations in this work suggest that a large fraction of mercury in thunderstorm rainwater is scavenged from the free troposphere. The numerical modeling experiments show that meteorological conditions, which differ between regions of the US, influence the storm dynamics and scavenging efficiency of convective storms. Further work is needed to assess mercury scavenging in frontal and mesoscale convective systems and airborne mercury observations in conjunction with event-based storm modeling would provide a valuable additional test of how efficiently mercury is scavenged and deposited by rainclouds.

Acknowledgements. This research is supported by EPRI. We thank several reviewers for their valuable contributions to improve this work.

Edited by: R. Volkamer

\section{References}

Amos, H. M., Jacob, D. J., Holmes, C. D., Fisher, J. A., Wang, Q., Yantosca, R. M., Corbitt, E. S., Galarneau, E., Rutter, A. P., Gustin, M. S., Steffen, A., Schauer, J. J., Graydon, J. A., Louis, V. L. St., Talbot, R. W., Edgerton, E. S., Zhang, Y., and Sunderland, E. M.: Gas-particle partitioning of atmospheric $\mathrm{Hg}(\mathrm{II})$ and its effect on global mercury deposition, Atmos. Chem. Phys., 12, 591-603, doi:10.5194/acp-12-591-2012, 2012.

Barth, M. C., Stuart, A. L., and Skamarock, W. C.: Numerical simulations of the July 10 Stratospheric-Tropospheric Experiment: Radiation, Aerosols and Ozone/Deep Convection storm: Redistribution of soluble tracers, J. Geophys. Res., 106, 1238112400., 2001.

Barth, M. C., Kim, S.-W., Wang, C., Pickering, K. E., Ott, L. E., Stenchikov, G., Leriche, M., Cautenet, S., Pinty, J.-P., Barthe, Ch., Mari, C., Helsdon, J. H., Farley, R. D., Fridlind, A. M., Ackerman, A. S., Spiridonov, V., and Telenta, B.: Cloud-scale model intercomparison of chemical constituent transport in deep convection, Atmos. Chem. Phys., 7, 4709-4731, doi:10.5194/acp-74709-2007, 2007.

Bullock, O. R., Atkinson, D., Braverman, T., Civerolo, K., Dastoor, A., Davignon, D., Ku, J. Y., Lohman, K., Myers, T. C., Park, R. J., Seigneur, C., Selin, N. E., Sistla, G., and Vijayaraghavan, K.: An analysis of simulated wet deposition of mercury from the North American Mercury Model Intercomparison Study, J. Geophys. Res., 114, D08301, doi:10.1029/2008JD011224, 2009.

Coburn, S., Dix, B., Sinreich, R., and Volkamer, R.: The CU ground MAX-DOAS instrument: characterization of RMS noise limitations and first measurements near Pensacola, FL of BrO, IO, and CHOCHO, Atmos. Meas. Tech., 4, 2421-2439, doi:10.5194/amt-4-2421-2011, 2011.

Cotton, W. R., Alexander, G. D., Hertenstein, R., Walko, R. L., McAnelly, R. L., and Nicholls, M.: Cloud Venting - A review and some new global annual estimates, Earth-Sci. Rev., 39, 169206, 1995.

Cotton, W. R., Pielke Sr., R. A., Walko, R. L., Liston, G. E., Tremback, C., Jiang, H., McAnelly, R. L., Harrington, J. Y., Nicholls, M. E., Carrio, G. G., and McFadden, J. P.: RAMS 2001: Current status and future directions, Meteor. Atmos. Phys., 82, 5-29, 2003.

Cohen, C.: A quantitative investigation of entrainment and detrainment in numerically simulated cumulonimbus clouds, J. Atmos. Sci., 57, 1657-1674, 2000.

Cohen, C. and McCaul Jr., E. W.: The sensitivity of simulated convective storms to variations in prescribed single moment microphysics parameters that describe particle distributions, sizes, and numbers, Mon. Weather Rev., 134, 2547-2565, 2006.

Dickerson, R. R., Huffman, G. J., Luke, W. T., Nunnermacker, L. J., Pickering, K. E., Leslie, A. C. D., Lindsey, C. G., Slinn, W. G. N., Kelly, T. J., Daum, P. H., Delany, A. C., Greenberg, J. P., Zimmerman, P. R., Boatman, J. F., Ray, J. D., and Stedman, D. H.: Thunderstorms - An important mechanism in the transport of air pollutants, Science, 235, 460-464, 1987.

Douglas, T. A., Sturm, M., Simpson, W. R., Blum, J. D., AlvarezAviles, L., Keeler, G. J., Perovich, D. K., Biswas, A., and Johnson, K.: Influence of snow and ice crystal formation and accumulation on mercury deposition to the Arctic, Environ. Sci. Technol., 42, 1542-1551, doi:10.1021/es070502d, 2008. 
Dvonch, J. T., Graney, J. R., Marsik, F. J., Keeler, G. J., and Stevens, R. K.: An investigation of source-receptor relationships for mercury in south Florida using event precipitation data, Sci. Total Environ., 213, 95-108, 1998.

Dvonch, J. T., Keeler, G. J., and Marsik, F. J.: The influence of meteorological conditions on the wet deposition of mercury in southern Florida, J. Appl. Meteorol., 44, 1421-1435, 2005.

Edgerton, E. S., Hartsell, B. E., and Jansen, J. J.: Mercury speciation in coal-fired power plant plumes observed at three surface sites in the southeastern US, Environ. Sci. Technol., 40, 4563-4570, doi:10.1021/es0515607, 2006.

Environmental Protection Agency: 2010 Biennial Listing of Fish Advisories, Technical Report EPA-820-F-11014, http://water.epa.gov/scitech/swguidance/fishshellfish/ fishadvisories/upload/technical_factsheet_2010.pdf (last access: 15 November 2012), 2011.

Environmental Protection Agency: 2008 National Emissions Inventory, http://www.epa.gov/ttnchie1/eiinformation.html, last access: 18 June 2013.

Feddersen, D. M., Talbot, R., Mao, H., and Sive, B. C.: Size distribution of particulate mercury in marine and coastal atmospheres, Atmos. Chem. Phys., 12, 10899-10909, doi:10.5194/acp-1210899-2012, 2012.

Feng, H.: A 3-mode parameterization of below-cloud scavenging of aerosols for use in atmospheric dispersion models, Atmos. Environ., 41, 6808-6822, doi:10.1016/j.atmosenv.2007.04.046, 2007.

Feng, J.: A size-resolved model for below-cloud scavenging of aerosols by snowfall, J. Geophys. Res.-Atmos., 114, D08203, doi:10.1029/2008JD011012, 2009.

Gillani, N. V., Schwartz, S. E., Leaitch, W. R., Strapp, J. W., and Isaac, G. A.: Field observations in continental stratiform clouds: Partitioning of cloud particles between droplets and unactivated interstitial aerosols, J. Geophys. Res., 100, 18687, doi:10.1029/95JD01170, 1995.

Guentzel, J. L., Landing, W. M., Gill, G. A., and Pollman, C. D.: Processes influencing rainfall deposition of mercury in Florida, Environ. Sci. Technol., 35, 863-873, 2001.

Halland, J. J., Fuelberg, H. E., Pickering, K. E., and Luo, M.: Identifying convective transport of carbon monoxide by comparing remotely sensed observations from TES with cloud modeling simulations, Atmos. Chem. Phys., 9, 4279-4294, doi:10.5194/acp9-4279-2009, 2009.

Holmes, C. D.: Thunderstorms increase mercury concentration in rainfall, in preparation, 2013.

Holmes, C. D., Jacob, D. J., Corbitt, E. S., Mao, J., Yang, X., Talbot, R., and Slemr, F.: Global atmospheric model for mercury including oxidation by bromine atoms, Atmos. Chem. Phys. Discuss., 10, 19845-19900, doi:10.5194/acpd-10-19845-2010, 2010a.

Holmes, C. D., Jacob, D. J., Samath, N., Landing, W., Fuelberg, H. E., Rudlosky, S. D., Caffrey, J., and Edegeron, E.: Thunderstorms increase mercury concentration in rainfall, Presented at Goldschmidt Conference, Knoxville, Tennessee, USA, 2010b.

Jensen, J. B. and Charlson, R. J.: On the efficiency of nucleation scavenging, Tellus B, 36B, 367-375, doi:10.1111/j.16000889.1984.tb00255.x, 1984.

Johnson, K. P., Blum, J. D., Keeler, G. J., and Douglas, T. A.: Investigation of the deposition and emission of mercury in arctic snow during an atmospheric mercury depletion event, J. Geophys. Res., 113, D17304, doi:10.1029/2008JD009893, 2008.
Karouna-Renier, N., Rao, K., Lanza, J., Rivers, S., Wilson, P., Hodges, D., Levine, K., and Ross, G: Mercury levels and fish consumption practices in women of child-bearing age in the Florida Panhandle, Environ. Res., 108, 320-326, 2008.

Kirkpatrick, C., McCaul Jr., E. W., and Cohen, C.: The motion of simulated convective storms as a function of basic environmental parameters, Mon. Weather Rev., 135, 3033-3051, 2007.

Kirkpatrick, C., McCaul Jr., E. W., and Cohen, C.: Sensitivities of Simulated Convective Storms to Environmental CAPE, Mon. Weather Rev., 139, 3514-3532, 2011.

Knupp, K. R. and Cotton, W. R.: Convective cloud downdraft structure: An interpretive survey, Rev. Geophys., 23, 183-215, 1985.

Landing, W. M., Caffrey, J. M., Nolek, S. D., Gosnell, K. J., and Parker, W. C.: Atmospheric wet deposition of mercury and other trace elements in Pensacola, Florida, Atmos. Chem. Phys., 10, 4867-4877, doi:10.5194/acp-10-4867-2010, 2010.

Levine, S. Z. and Schwartz, S. E.: In-cloud and below-cloud scavenging of nitric acid vapor, Atmos. Environ., 16, 1725-1734, 1982.

Lindberg, S., Bullock, R., Ebinghaus, R., Engstrom, D., Feng, X., Fitzgerald, W., Pirrone, N., Prestbo, E., and Seigneur, C.: A synthesis of progress and uncertainties in attributing the sources of mercury in deposition, Ambio, 36, 19-32, 2007.

Lin, C. and Pehkonen, S.: The chemistry of atmospheric mercury: a review, Atmos. Environ., 33, 2067-2079, 1999.

Liu, G., Cai, Y., Kalla, P., Scheidt, D., Richards, J., Scinto, L. J., Gaiser, E., and Appleby, C.: Mercury mass budget estimates and cycling seasonality in the Florida everglades, Environ. Sci. Technol., 42, 1954-1960, doi:10.1021/es7022994, 2008.

Lyman, S. N. and Jaffe, D. A.: Formation and fate of oxidized mercury in the upper troposphere and lower stratosphere, Nat. Geosci., 5, 114-117, doi:10.1038/ngeo1353, 2012.

Mari, C., Jacob, D. J., and Bechtold, P.: Transport and scavenging of soluble gases in a deep convective cloud, J. Geophys. Res., 105, 22255-22267, doi:10.1029/2000JD900211, 2000.

McCaul Jr., E. W. and Weisman, M. L.: The sensitivity of simulated supercell structure and intensity to variations in the shapes of environmental buoyancy and shear profiles, Mon. Weather Rev., 129, 664-687, 2001.

McCaul Jr., E. W., Cohen, C., and Kirkpatrick, C.: The sensitivity of simulated storm structure, intensity, and precipitation efficiency to the temperature at the lifted condensation level, Mon. Weather Rev., 133, 3015-3037, 2005.

Meyers, M. P., Walko, R. L., Harrington, J. Y., and Cotton, W. R.: New RAMS cloud microphysics parameterization. Part II: The two-moment scheme, Atmos. Res., 45, 3-39, 1997.

Murakami, M., Kimura, T., Magono, C., and Kikuchi, K.: Observations of precipitation scavenging for water-soluble particles, J. Meteor. Soc. Jpn., 61, 346-358, 1983.

Murphy, D. M., Hudson, P. K., Thomson, D. S., Sheridan, P. J., and Wilson, J. C.: Observations of Mercury-Containing Aerosols, Environ. Sci. Technol., 40, 3163-3167, doi:10.1021/es052385x, 2006.

Nair, U. S., McCaul, E. W., and Welch, R. M.: Climatology of environmental parameters that influence severe storm intensity and morphology. Preprints, 16th Conference on Hydrology, 13-17 January 2002, Orlando, FL, Amer. Meteor. Soc., 58-60, 2002.

National Atmospheric Deposition Program: National Atmospheric Deposition Program 2009 Annual Summary, NADP Data Report 
2010-01, Illinois State Water Survey, University of Illinois at Urbana-Champaign, IL, 2010.

Northeast Regional Mercury Total Maximum Daily Load: http://www.epa.gov/region1/eco/tmdl/pdfs/ne/ tmdl-Hg-approval-doc.pdf (last access: 15 November 2012), 2007.

Seinfeld, J. H. and Pandis, S. N.: Atmospheric Chemistry and Physics: From Air Pollution to Climate Change, 2nd Edn., J. Wiley, New York, 2006.

Selin, N. E. and Jacob, D. J.: Seasonal and spatial patterns of mercury wet deposition in the United States: Constraints on the contribution from North American anthropogenic sources, Atmos. Environ., 42, 5193-5204, doi:10.1016/j.atmosenv.2008.02.069, 2008.

Shanley, J. B., Engle, M. A., Scholl, M. A., Krabbenhoft, D. P., Brunette, R., and Olson, M. L.: High mercury wet deposition at a Clean air: site in Puerto Rico, Session TG4B-P17, Atmospheric Mercury: Measurement and Monitoring, The 10th International Conference on Mercury as Global Pollutant, 24-29 July 2011, Halifax, Nova Scotia, Canada, 2011.

Sigler, J. M., Mao, H., and Talbot, R.: Gaseous elemental and reactive mercury in Southern New Hampshire, Atmos. Chem. Phys., 9, 1929-1942, doi:10.5194/acp-9-1929-2009, 2009.

Sillman, S., Marsik, F. J., Al-Wali, K. I., Keeler, G. J., and Landis, M. S.: Reactive mercury in the troposphere: Model formation and results for Florida, the northeastern United States, and the Atlantic Ocean, J. Geophys. Res.-Atmos., 112, D23305, doi:10.1029/2006JD008227, 2007.

Slemr, F., Ebinghaus, R., Brenninkmeijer, C. A. M., Hermann, M., Kock, H. H., Martinsson, B. G., Schuck, T., Sprung, D., van Velthoven, P., Zahn, A., and Ziereis, H.: Gaseous mercury distribution in the upper troposphere and lower stratosphere observed onboard the CARIBIC passenger aircraft, Atmos. Chem. Phys., 9, 1957-1969, doi:10.5194/acp-9-1957-2009, 2009.
Subir, M., Ariya, P. A., and Dastoor, A. P.: A review of uncertainties in atmospheric modeling of mercury chemistry I. Uncertainties in existing kinetic parameters - Fundamental limitations and the importance of heterogeneous chemistry, Atmos. Environ., 45, 5664-5676, doi:10.1016/j.atmosenv.2011.04.046, 2011.

Talbot, R., Mao, H., Scheuer, E., Dibb, J., and Avery, M.: Total depletion of $\mathrm{Hg}^{0}$ in the upper troposphere-lower stratosphere, Geophys. Res. Lett., 34, L23804, doi:10.1029/2007GL031366, 2007.

Valente, R. J., Shea, C., Humes, K. L., and Tanner, R. L.: Atmospheric mercury in the Great Smoky Mountains compared to regional and global levels, Atmos. Environ., 41, 1861-1873, doi:10.1016/j.atmosenv.2006.10.054, 2007.

Voudouri, A. and Kallos, G.: Validation of the integrated RAMS-Hg modeling system using wet deposition observations for eastern North America, Atmos. Environ., 41, 5732-5745, 2007.

Walko, R. L., Cotton, W. R., Meyers, M. P., and Harrington, J. Y.: New RAMS cloud microphysics parameterization. Part I: the single-moment scheme, Atmos. Res., 38, 29-62, 1995.

White, E. M., Keeler, G. J., and Landis, M. S.: Spatial variability of mercury wet deposition in eastern Ohio: summertime meteorological case study analysis of local source influences, Environ. Sci. Technol., 43, 4946-4953, 2009.

Yin, Y., Parker, D. J., and Carslaw, K. S.: Simulation of trace gas redistribution by convective clouds - Liquid phase processes, Atmos. Chem. Phys., 1, 19-36, doi:10.5194/acp-1-19-2001, 2001.

Zhang, Y., Jaeglé, L., van Donkelaar, A., Martin, R. V., Holmes, C. D., Amos, H. M., Wang, Q., Talbot, R., Artz, R., Brooks, S., Luke, W., Holsen, T. M., Felton, D., Miller, E. K., Perry, K. D., Schmeltz, D., Steffen, A., Tordon, R., Weiss-Penzias, P., and Zsolway, R.: Nested-grid simulation of mercury over North America, Atmos. Chem. Phys., 12, 6095-6111, doi:10.5194/acp12-6095-2012, 2012. 